\title{
'Spoon-Fed' Versus Self-Directed Learning in an Arab Context
}

\section{التلقين مقابل التعلم الذاتي في السياق العربي}

Dear Editor,

During my many years of teaching, planning and research at both undergraduate and postgraduate medical education institutions in Saudi Arabia, I have witnessed the establishment of new learning environments following the adaptation of different curricula and application of new teaching and learning strategies, such as problem-based learning (PBL). ${ }^{1}$ However, it is debatable whether such environments are conducive for learning in Saudi Arabia and whether they will produce independent self-directed and lifelong learners. While people in various parts of the world have different lifestyles, they also think in distinctly different ways. ${ }^{2}$ Countries with predominantly Arab cultures, especially in the Middle East, have their own traditions that reflect varying elements of achievement, hierarchy and uncertainty. This may therefore complicate attempts to simply transfer existing skill-based systems from Western to Arab countries. ${ }^{2}$

In secondary schools with teacher-centred educational systems, students are generally less independent within the learning process; one might claim that such students are 'spoon-fed' the requisite knowledge by their teachers. ${ }^{3,4}$ Furthermore, the examination process encourages students to focus solely on their grades, inhibiting them from learning information outside of the set curricula. Unfortunately, the expectation of being 'spoon-fed' is often carried on from secondary school to medical school. This deters self-directed learning (SDL), which incorporates highly useful skills, particularly when subsequently entering a demanding and challenging learning environment such as a medical school. ${ }^{5}$ Graduating from a secondary school to a medical school presents a transitional challenge for many students due to the lack of academic rigour, self-motivation and dedication to lifelong learning necessary to become a competent physician.

In general, many students favour a 'spoon-feeding' learning approach because it provides easy access to the right answers. However, such methods give students the incorrect impression that such knowledge is known to or accessible only via their teachers. ${ }^{3}$ As a result, it is common for students who have been 'spoon-fed' to only be capable of regurgitating information they have been told. ${ }^{6}$ In situations wherein students lack SDL skills, exposing first-year medical students to an independent learning environment without guidance may cause difficulties. Consequently, students may feel forced to turn to tutors, follow predetermined learning objectives or partake in rote learning in order to maintain their grade point average. ${ }^{6,7}$ This results in students who either attempt to apply rote learning during examinations or are not able to answer examination questions at all.

Overall, PBL involves a constructivist approach whereby students build new knowledge upon prior knowledge. ${ }^{1}$ However, the acquirement of new knowledge requires time. Therefore, instead of expecting Arab students to take part in a fully independent SDL approach, such students should be guided towards directed self-learning. ${ }^{8,9}$ This approach provides initial guidance and a support system for students, thereby offering more time to acquire new knowledge and develop SDL skills. In addition, medical educators should create a grassroots strategy for the development of self-regulation skills in order to enable these future physicians to become selfdirected lifelong learners. ${ }^{10}$

\author{
Abdul S. Khan \\ Department of Family \& Community Medicine, King Faisal University, Hafuf, Saudi Arabia \\ E-mails: yardockhan.ask@gmail.com and amkhan@kfu.edu.sa
}




\section{References}

1. Bielenberg B, Gillway M. Adapting problem-based learning to meet the life-long learning needs of developmental students. Learn Teach High Educ Gulf Perspect 2007; 4:1-13.

2. Hofstede G. Culture's Consequences: Comparing values, behaviors, institutions, and organizations across nations, 2nd ed. Thousand Oaks, California, USA: Sage Publications Inc., 2003. Pp. 1-40.

3. Dehler GE, Welsh MA. Against spoon-feeding: For learning - Reflections on students' claims to knowledge. J Manag Educ 2014; $38: 875-93$. doi: $10.1177 / 1052562913511436$.

4. Smith H. Spoon-feeding: Or how I learned to stop worrying and love the mess. Teach High Educ 2008; 13:715-18. doi: 10.1080/13 562510802452616.

5. Frambach JM, Driessen EW, Chan LC, van der Vleuten CP. Rethinking the globalization of problem-based learning: How culture challenges self-directed learning. Med Educ 2012; 46:738-47. doi: 10.1111/j.1365-2923.2012.04290.x.

6. McKay J, Kember D. Spoon feeding leads to regurgitation: A better diet can result in more digestible learning outcomes. High Educ Res Dev 1997; 16:55-67. doi: 10.1080/0729436970160105.

7. Loyens SM, Magda J, Rikers RM. Self-directed learning in problem-based learning and its relationships with self-regulated learning. Educ Psychol Rev 2008; 20:411-27. doi: 10.1007/s10648-008-9082-7.

8. Miflin BM, Campbell CB, Price DA. A lesson from the introduction of a problem-based, graduate entry course: The effects of different views of self-direction. Med Educ 1999; 33:801-7. doi: 10.1046/j.1365-2923.1999.00399.x.

9. Brydges R, Dubrowski A, Regehr G. A new concept of unsupervised learning: Directed self-guided learning in the health professions. Acad Med 2010; 85:S49-55. doi: 10.1097/ACM.0b013e3181ed4c96.

10. Lens W, Vansteenkiste M. Promoting self-regulated learning: A motivational analysis. In: Schunk DH, Zimmerman BJ (Eds). Motivation and Self-Regulated Learning: Theory, research, and applications. Abingdon, UK: Routledge, 2007. Pp. 141-68. 